\title{
Shallow inland earthquakes in NE Japan possibly triggered by the 2011 off the Pacific coast of Tohoku Earthquake
}

\author{
Tomomi Okada ${ }^{1}$, Keisuke Yoshida $^{1}$, Sadato Ueki $^{1}$, Junichi Nakajima ${ }^{1}$, Naoki Uchida ${ }^{1}$, Toru Matsuzawa ${ }^{1}$, \\ Norihito Umino $^{1}$, Akira Hasegawa ${ }^{1}$, and Group for the aftershock observations \\ of the 2011 off the Pacific coast of Tohoku Earthquake ${ }^{2}$ \\ ${ }^{1}$ Research Center for Prediction of Earthquakes and Volcanic Eruptions, Graduate School of Science, Tohoku University, \\ 6-6 Aramaki-Aza-Aoba, Aoba-ku, Sendai 980-8578, Japan \\ ${ }^{2}$ The members of the group are listed at the end of this paper.
}

(Received April 26, 2011; Revised June 16, 2011; Accepted June 17, 2011; Online published September 27, 2011)

\begin{abstract}
Shallow seismic activity in the crust of the overriding plate west of the source area increased significantly after the $2011 M_{\mathrm{w}} 9.0$ Tohoku earthquake which ruptured the plate boundary to the east off northern Japan beneath the Pacific Ocean. In order to understand the cause of this distinctive change in seismicity, we have precisely relocated earthquake hypocenters for several earthquake sequences that occurred during the period March 11-April 6, 2011, following the Tohoku earthquake by the double-difference method. Hypocenter distributions were used to discriminate the fault plane from the auxiliary plane of the focal mechanisms for those earthquake sequences. We then calculated the Coulomb stress change on those fault planes caused by the $2011 M_{\mathrm{w}} 9$ earthquake. In all cases, the estimated Coulomb stress changes at the plausible fault planes for those post-mainshock sequences are positive. The positive Coulomb stress change is mainly due to the reduction of normal stress on the fault plane of the earthquake sequences by the large, low-angle thrust fault responsible for the $2011 M_{\mathrm{w}} 9$ earthquake. The present observations suggest that static stress transfer possibly triggered those post-mainshock earthquake sequences.
\end{abstract}

Key words: Triggered earthquake, focal mechanism, hypocenter distribution, Coulomb stress change.

\section{Introduction}

Following the $2011 M_{\mathrm{w}} 9.0$ Tohoku earthquake, there occurred not only aftershocks near the source fault along the plate boundary, but also many shallow earthquakes occurred at several locations in the overriding plate. Figure 1 shows the hypocenters of inland earthquakes that occurred in NE Japan after the 2011 Tohoku Earthquake based on the Japan Meteorological Agency (JMA) catalog. The epicenters of earthquakes which occurred after the 2011 Tohoku earthquake are distributed close to areas of high seismicity prior to the 2011 Tohoku earthquake.

One typical example of a large inland earthquake that occurred after a large interplate earthquake in NE Japan is the $1896 M 7.2$ Riku-u earthquake. The earthquake occurred 2.5 months after the 1896 M 8 Sanriku tsunami earthquake (e.g. Kanamori, 1972). Ohtake (1997) suggested the possibility that the reduction of normal stress by the Sanriku earthquake triggered the Riku-u earthquake if the fault plane of the Riku-u earthquake was steeply dipping, although the fault has been estimated to be possibly not steeply dipping in later studies $\left(\sim 30^{\circ}\right.$; from Sato et al., 2002).

To understand the cause of such activation of seismicity in the overriding plate by a large interplate earthquake, we

Copyright (C) The Society of Geomagnetism and Earth, Planetary and Space Sciences (SGEPSS); The Seismological Society of Japan; The Volcanological Society of Japan; The Geodetic Society of Japan; The Japanese Society for Planetary Sciences; TERRAPUB.

doi: $10.5047 /$ eps.2011.06.027 need to know the geometry of the fault plane and the slip on it. In this study, we have investigated, in detail, hypocenter distributions of several events that occurred after the $M_{\mathrm{w}} 9.0$ earthquake in order to discriminate the fault plane from the auxiliary plane of the focal mechanism. We then calculated the Coulomb stress change (Lin and Stein, 2004; Toda et al., 2005) on each fault attributable to the $2011 M_{\mathrm{w}} 9.0$ Tohoku Earthquake to explore whether or not they were likely triggered by the $M_{\mathrm{w}} 9.0$ event.

\section{Determination of the Fault Plane by Focal Mechanism and Relocated Hypocenters}

We selected several remarkable sequences of inland earthquakes in the NE Honshu area during the period from March 11 to April 6, whose focal mechanisms have been determined. The focal mechanisms are from GCMT (Nettles et al., 2011), AQUA-CMT by the National Institute for Earth Sciences and Disaster Prevention (NIED) (http://www.hinet.bosai.go.jp), and the Japan Meteorological Agency (JMA) CMT (http://www.jma.go.jp). For smaller events, whose focal mechanisms were not reported, we determined focal mechanisms using the polarities of $P$-waves by the HASH program (Hardebeck and Shearer, 2002).

To discriminate which of the two nodal planes is the plausible fault plane, we compare the hypocenter distribution with the focal mechanism. We employ a doubledifference (DD) hypocenter location method (Waldhauser and Ellsworth, 2000; Waldhauser, 2001) to precisely relo- 


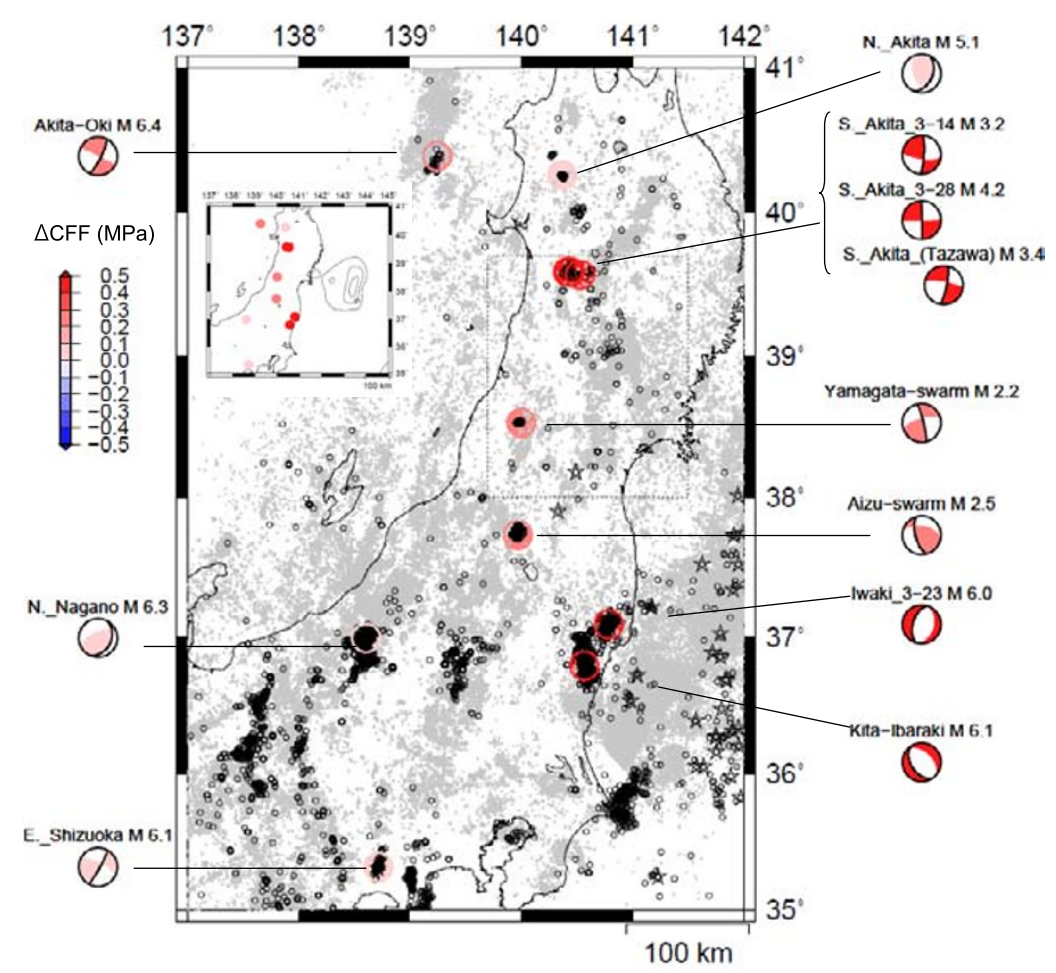

Fig. 1. Hypocenters of inland earthquakes that occurred in NE Japan based on the Japan Meteorological Agency (JMA) catalog. Inland earthquakes before, and after, the 2011 Tohoku Earthquake are shown by gray and black circles, respectively. A star denotes the earthquakes whose magnitudes are greater than 5. The color of the large circle denotes the amount of the Coulomb stress change caused by the $2011 M 9$ earthquake for each fault assumed in this study. The focal mechanisms with the plausible fault plane defined by the bold great circle are also shown. The area of Fig. 4 is outlined by a rectangle with broken line. The insert map shows the slip distribution by Hayes with a contour interval of $10 \mathrm{~m}$.

cate the individual hypocenters for those inland earthquake sequences. In the case of smaller events (Subsections 2.1,2, 3 , and 4), we used the travel-time difference data for nearby events calculated by the cross-correlation analysis of seismic waveforms.

Data are from the seismic networks of Tohoku University and other Japanese Universities, JMA, and NIED Hi-net. We also used data from six telemetry stations deployed just after the 2011 earthquake by the Group for the aftershock observations of the 2011 off the Pacific coast of Tohoku Earthquake, and those from temporary seismic stations and volcano observation stations operated by Tohoku University.

The focal mechanisms and the plausible fault planes for the relocated hypocenters are also shown in Fig. 1. We show fault geometries of the earthquakes in Subsections 2.1 to 2.9. We show two examples in detail: a larger event-the $M_{\text {jma }} 5.1$ event in northern Akita (2.1) and a smaller eventthe $M_{\text {jma }} 3.4$ event in central Akita (2.2).

\subsection{Northern Akita $\left(M_{\text {jma }} 5.1\right.$, 19:49 JST (10:49 UT) April 1)}

An $M 5.1$ event occurred at 19:49 JST (10:49 UT), April 1 in the northern part of Akita Prefecture accompanied by aftershocks. The epicenter of this event was about $15 \mathrm{~km}$ east from that of the 1955 M 5.5 Futatsui earthquake. For this M 5.1 earthquake, AQUA-CMT and JMA CMT show similar reverse-type focal mechanisms. We relocated the event and its aftershocks by a DD relocation method. The mainshock and three foreshocks and the 46 aftershocks were relocated with the hypocenter distribution shown in

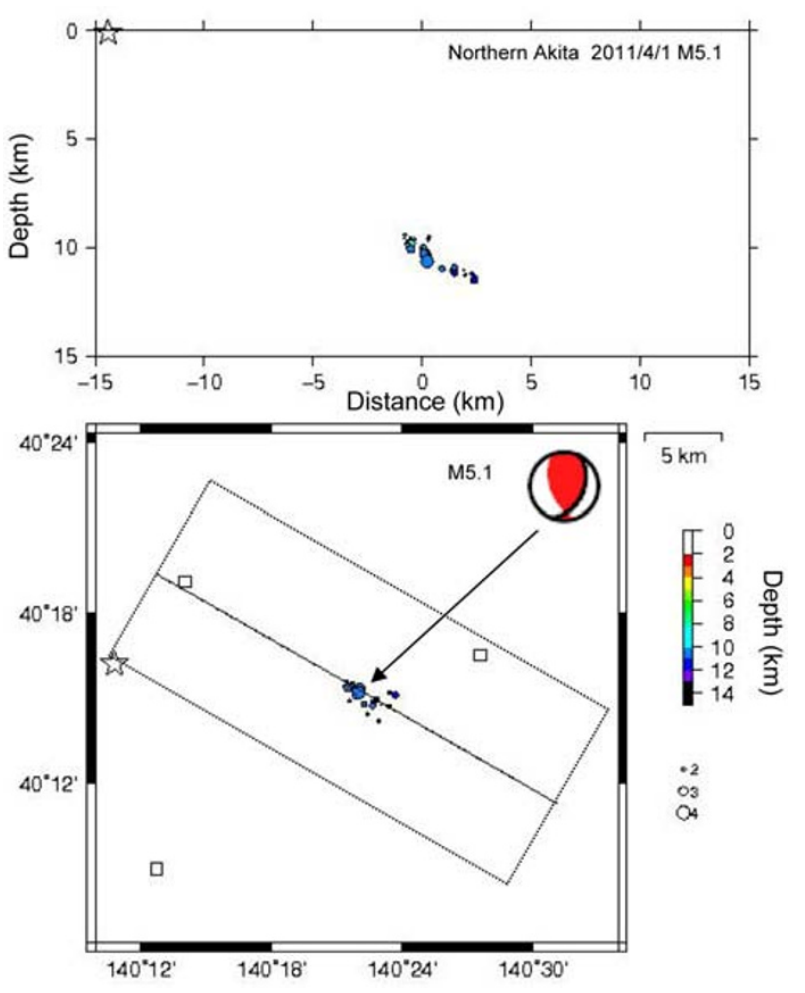

Fig. 2. Hypocenter distribution for the northern Akita $M 5.1$ earthquake. The star shows the location of the 1955 Futatsui $M 5.5$ earthquake by JMA (note: the depth is not well known). The bottom figure shows the epicenter distribution. Squares denote the seismograph stations in this area. The top figure is a vertical cross-section along the line in the epicenter map within $5 \mathrm{~km}$. AQUA-CMT is also shown. 
Fig. 2. The root-mean-squared (RMS) residual decreased from $0.14 \mathrm{~s}$ to $0.07 \mathrm{~s}$ by the relocation. Aftershocks align along a plane dipping eastward. Therefore, we assume that this eastward-dipping aftershock alignment corresponds to the fault plane of the $M 5.1$ event.

\subsection{Central Akita swarm}

Figure 3 shows the case of an earthquake swarm in the central part of Akita Prefecture. This swarm is located near the northern edge of the aftershock area of the 1914 M 7.1 Akita-Senboku earthquake. We relocated 72 events. The RMS residual decreased from $0.33 \mathrm{~s}$ to $0.09 \mathrm{~s}$ by the relocation. We determined the focal mechanism of an $M 3.4$ event that occurred at 18:19 JST (9:19 UT), March 30, near Lake Tazawa in the central part of Akita Prefecture. A group, including the $M 3.4$ event, seems to align with an $\mathrm{N}-\mathrm{S}$ strike, which almost corresponds with one nodal plane of the focal mechanism. This is located just beneath the surface trace of the Senya fault which may be the causative structure of the 1896 Riku-u earthquake, and appears to be an eastward-dipping reverse fault (Sato et al., 2002).

We also determined the focal mechanisms of the $M_{\text {jma }} 3.2$ event at 7:38 JST March 14 (22:38 UT, March 13) and $M_{\text {jma }} 4.2$ event at 14:38 JST March 28 (5:38 UT, March 28) of this swarm. Those mechanisms are of the strike-slip type. For each event, the aftershock seems to align with an N-S strike, which corresponds with one nodal plane of the focal mechanism.

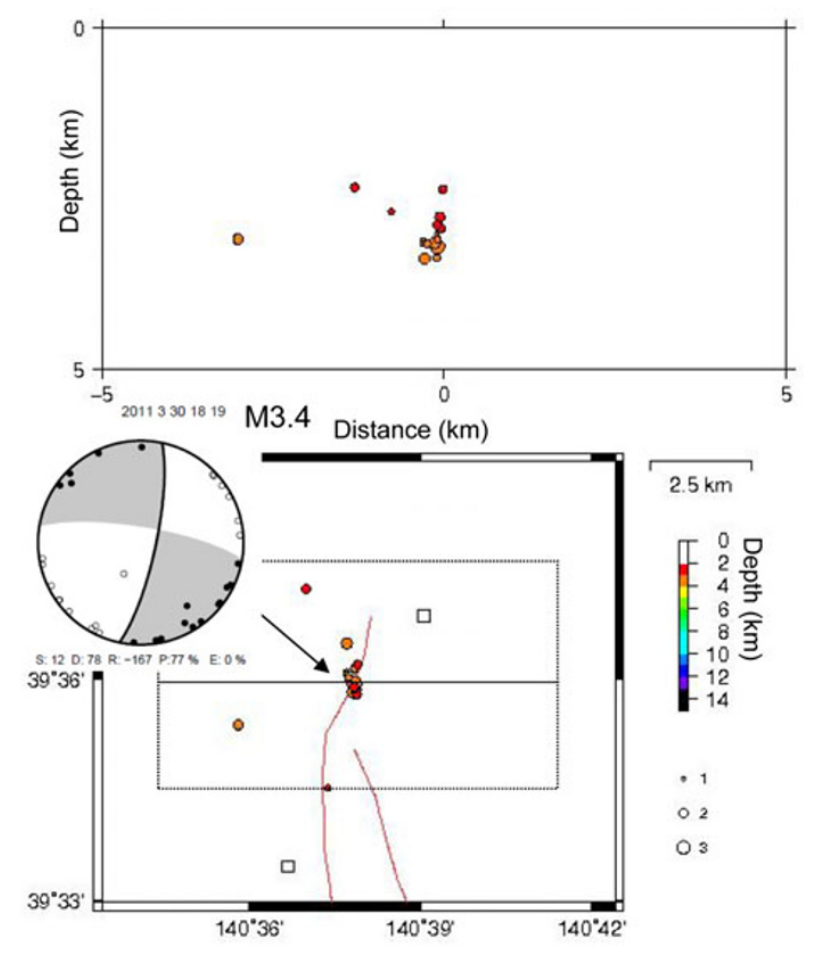

Fig. 3. Hypocenter distribution for the M 3.4 earthquake sequence near Lake Tazawa in central Akita. The bottom figure shows the epicenter distribution. Squares denote the seismograph stations in this area. Red lines show the surface trace of the active fault. The top figure gives the vertical cross-section for earthquakes lying within $\pm 3 \mathrm{~km}$ of the line in the epicenter map. The inferred rupture plane is shown in bold on the focal mechanism.

\subsection{Yamagata-Gassan swarm}

In the case of a seismic swarm in the central part of Yamagata Prefecture, we determined the focal mechanisms of an $M_{\text {jma }} 2.2$ event at 19:43 JST (10:43 UT), April 4. This mechanism is a strike-slip type with a slight component of reverse slip. We determined the hypocenter distribution of this cluster. We relocated 36 events. The RMS residual decreased from $0.11 \mathrm{~s}$ to $0.07 \mathrm{~s}$ by the relocation. A cluster, including the $M_{\text {jma }} 2.2$ event, seems to align with a strike of N-S and eastward dipping, which corresponds with one nodal plane of the focal mechanism. We assume this N-S striking plane to be the dominant fault plane in the earthquake sequence.

\subsection{Aizu swarm}

In the case of a seismic swarm in the northern part (Aizu district) of Fukushima Prefecture, we determined focal mechanism of an $M_{\text {jma }} 2.5$ event that occurred at 22:02 JST (13:02 UT), March 20. This mechanism is intermediate between strike-slip and a reverse-fault type. We determined the hypocenter distribution of this cluster, and relocated 528 events. The RMS residual decreased from $0.16 \mathrm{~s}$ to $0.08 \mathrm{~s}$ by the relocation. Events of the cluster near the $M 2.5$ event seem to align with a NNW-SSE strike, which corresponds with one nodal plane of the focal mechanism. We assume this plane with a NNW-SSE strike would be one of the fault planes of the earthquake swarm.

\subsection{Akita-Oki $\left(M_{\text {jma }}\right.$ 6.4, 04:46 JST March 12 (19:46 UT March 11))}

This event is located at the eastern edge of the aftershock area of the $1983 M 7.7$ Nihonkai-Chubu earthquake. The $M_{\text {jma }} 6.3$ event has a strike-slip focal mechanism with striking NNE-SSW according to the GCMT, although the 1983 $M 7.7$ earthquake was a thrust fault. We relocated 34 events of the sequence. The RMS residual decreased from $0.24 \mathrm{~s}$ to $0.15 \mathrm{~s}$ by the relocation. The hypocenters of these events align along a vertical plane striking NNE-SSW, which is taken to be the fault plane for the sequence.

\subsection{Iwaki $\left(M_{\text {jma }}\right.$ 6.0, 07:12 JST March 23 (22:12 UT March 22))}

The GCMT shows a normal-type focal mechanism with a strike of NNE-SSW. NIED AQUA-CMT and JMA CMT indicate similar conclusions. Hypocenters located by JMA seem to align along a westward-dipping plane. We also relocated 457 events until March 25. The RMS residual decreased from $0.15 \mathrm{~s}$ to $0.10 \mathrm{~s}$ by the relocation. The hypocenters of these events align along a westward-dipping plane. This plane is assumed to be the fault plane of this event.

\subsection{Kita-Ibaraki $\left(M_{\text {jma }}\right.$ 6.1 18:56 JST (9:56 UT) March 19)}

The GCMT shows a normal-type focal mechanism with a strike of NW-SE. NIED AQUA-CMT and JMA CMT are in agreement. The hypocenters of aftershocks from the $M_{\text {jma }} 6.1$ events align along a SW-dipping plane by NIED (http://www.hinet.bosai.go.jp/topics/nibaraki110319/). This plane is assumed to be the fault plane of the $M_{\text {jma }} 6.1$ event. 
Table 1. Calculated Coulomb stress change and normal stress change for each earthquake sequence. Normal stress is defined as positive for unclamping.

\begin{tabular}{|c|c|c|c|c|c|c|c|c|c|}
\hline \multirow[t]{2}{*}{ Region } & \multirow[t]{2}{*}{ Date (JST) } & \multirow[t]{2}{*}{$M$} & \multirow[t]{2}{*}{ Lat. } & \multirow[t]{2}{*}{ Lon. } & \multirow[t]{2}{*}{$h$} & \multicolumn{2}{|c|}{$\Delta \mathrm{CFF}(\mu=0.65)(\mathrm{MPa})$} & \multicolumn{2}{|c|}{ Normal Stress (MPa) } \\
\hline & & & & & & Plausible & Conjugate & Plausible & Conjugate \\
\hline N._Akita & Apr. 1, 2011 & 5.1 & 40.26 & 140.37 & 10 & 0.01 & -0.10 & 0.33 & 0.17 \\
\hline C._Akita_3-14 & Mar. 14, 2011 & 3.2 & 39.59 & 140.42 & 2 & 1.00 & 0.67 & 0.82 & 0.29 \\
\hline C._Akita_3-28 & Mar. 28, 2011 & 4.2 & 39.59 & 140.44 & 3 & 1.05 & 0.90 & 0.73 & 0.48 \\
\hline C._Akita_(Tazawa) & Apr. 3, 2011 & 3.4 & 39.57 & 140.53 & 3 & 1.22 & 0.86 & 0.96 & 0.36 \\
\hline Yamagata-swarm & Apr. 4, 2011 & 2.2 & 38.53 & 140.00 & 7 & 0.29 & -0.39 & 1.03 & 0.11 \\
\hline Aizu-swarm & Mar. 20, 2011 & 2.5 & 37.73 & 139.97 & 9 & 0.20 & -0.13 & 0.60 & 0.07 \\
\hline Akita-Oki & Mar. 12, 2011 & 6.4 & 40.39 & 139.25 & 16 & 0.20 & 0.08 & 0.27 & 0.02 \\
\hline Iwaki_3-23 & Mar. 23, 2011 & 6.0 & 37.09 & 140.79 & 7 & 0.60 & 0.34 & 0.47 & 0.08 \\
\hline Kita-Ibaraki & Mar. 19, 2011 & 6.1 & 36.79 & 140.57 & 6 & 0.44 & 0.37 & 0.27 & 0.15 \\
\hline N._Nagano & Mar. 12, 2011 & 6.3 & 36.99 & 138.61 & 8 & 0.01 & -0.01 & 0.04 & 0.01 \\
\hline E._Shizuoka & Mar. 15, 2011 & 6.1 & 35.32 & 138.72 & 15 & 0.02 & 0.03 & -0.01 & 0.06 \\
\hline
\end{tabular}

2.8 Northern Nagano $\left(M_{\text {jma }}\right.$ 6.3 3:59 JST, March 12 (21:59 JST, March 11))

We choose the reverse-type fault plane with a NESW strike dipping southeast by the GCMT and relocated hypocenters by NIED (http://www.hinet.bosai.go.jp/ topics/n-nagano110312/). Note that JMA-CMT provide a similar solution.

\subsection{Eastern Shizuoka $\left(M_{\text {jma }}\right.$ 6.1, 21:31 JST (13:31 UT),} March 15)

We choose the strike-slip-type fault plane with a strike of NNE-SSW by the GCMT and relocated hypocenters by NIED (http://www.hinet.bosai.go.jp/topics/eshizuoka110315/). NIED AQUA-CMT and JMA CMT give similar solutions.

\section{Calculation of Coulomb Stress Change}

For the fault planes discriminated from auxiliary planes in the previous section, we calculate the Coulomb stress change caused by the 2011 Tohoku earthquake. We also assume the rake from each focal mechanism. We adopted the Coulomb 3.2 (Lin and Stein, 2004; Toda et al., 2005), assuming a frictional coefficient of 0.65 . We calculate the static stress on each fault in a uniform and isotropic elastic half-space following Okada (1992). The shear modulus and Poisson's ratio are $3.2 \times 10^{4} \mathrm{MPa}$ and 0.25 , respectively. The Coulomb stress change is defined as: $\Delta \sigma_{\mathrm{f}}=\Delta \tau_{\mathrm{s}}+$ $\mu \Delta \sigma_{\mathrm{n}}$. Here, $\Delta \sigma_{\mathrm{f}}$ is the change in failure stress on each fault of the post-megathrust event by the source fault (the $2011 M_{\mathrm{w}} 9$ Tohoku earthquake), $\Delta \tau_{\mathrm{s}}$ is the change in shear stress, $\Delta \sigma_{\mathrm{n}}$ is the change in normal stress, and $\mu$ is the frictional coefficient. We used the slip model for the 2011 $M_{\mathrm{w}} 9$ earthquake provided by Hayes, USGS (Hayes, 2011).

Table 1 shows the result for the plausible fault planes for all the sequences. We also illustrate the amount of the Coulomb stress change by the color of the circles in Fig. 1. For all the fault planes, the calculated Coulomb stress change is positive, whereas the auxiliary planes of some sequences are not positive. We also used the slip model for the $2011 M_{\mathrm{w}} 9$ earthquake provided by Iinuma $e t$ al. (2011). This tendency of positive Coulomb stress is also estimated by the slip model by Iinuma et al. (2011). If we assume a smaller value of the friction coefficient (0.4), the Coulomb stress change is still positive except almost zero for the region of Subsection 2.1. The fault planes we have discriminated have a strike almost in the N-S direction or the NE-SW direction and this direction of strike is almost parallel to the strike of the fault of the $2011 M 9$ earthquake. The strike of the 2011 event is about 200 degrees (c.f. 194 degrees by Hayes; 203 degrees by GCMT). For these fault planes steeply dipping to the west of the large slip area of the 2011 M9 earthquake (except for the eastern Shizuoka earthquake), the normal stress on the fault decreases. The increase of the Coulomb stress change is mainly due to the reduction of normal stress for each fault due to the large reverse slip of the $2011 M 9$ earthquake.

\section{Discussion}

As shown in the previous section, the estimation of fault planes of earthquake sequences occurring just after the $M_{\mathrm{w}} 9.0$ earthquake and the calculation of associated Coulomb stress changes suggest that these post-megathrust events are triggered by the static stress change caused by the large slip along the plate boundary thrust that accompanied the $2011 M_{\mathrm{w}} 9$ earthquake.

These triggered earthquake sequences tend to be located in areas of high seismicity prior to the 2011 earthquake as shown in Fig. 1. However, if we consider this in more detail, we note that most of these earthquakes are located at the margin of the high-seismicity areas.

In NE Japan, these high-seismicity areas consist of many reverse-slip earthquake ruptures with EW or NW-SE oriented $P$-axes (e.g. Hasegawa et al., 2005). Toda (2011, http://www.rcep.dpri.kyotou.ac.jp/events/110311tohoku/toda/index.html) suggested that Coulomb stress changes for such "typical" reverse faults are negative except in the northernmost and southernmost part of NE Japan (i.e. the events 2.1 and 2.8 in this study). In this study, however, some of the post-megathrust events $(2.2,2.3,2.4$, and 2.5) in the central part of NE Japan yield strike-slip solutions with steeply-dipping fault planes $\left(>60^{\circ}\right)$ and NE-SW oriented $P$-axes. Their dip angle is greater than the lock-up angle for pure reverse faults under the usual stress field with the WNW-ESE directed and horizontal maximum compressional stress axis $\left(\sigma_{1}\right)$ in NE Japan (Sibson, 1990, 2009). A reduction of normal stress may have triggered the occurrence of these post events which could not occur before the $2011 M 9$ event.

There occurs a possible change in local stress regimes in 
$\mathrm{dVs}(\%)$

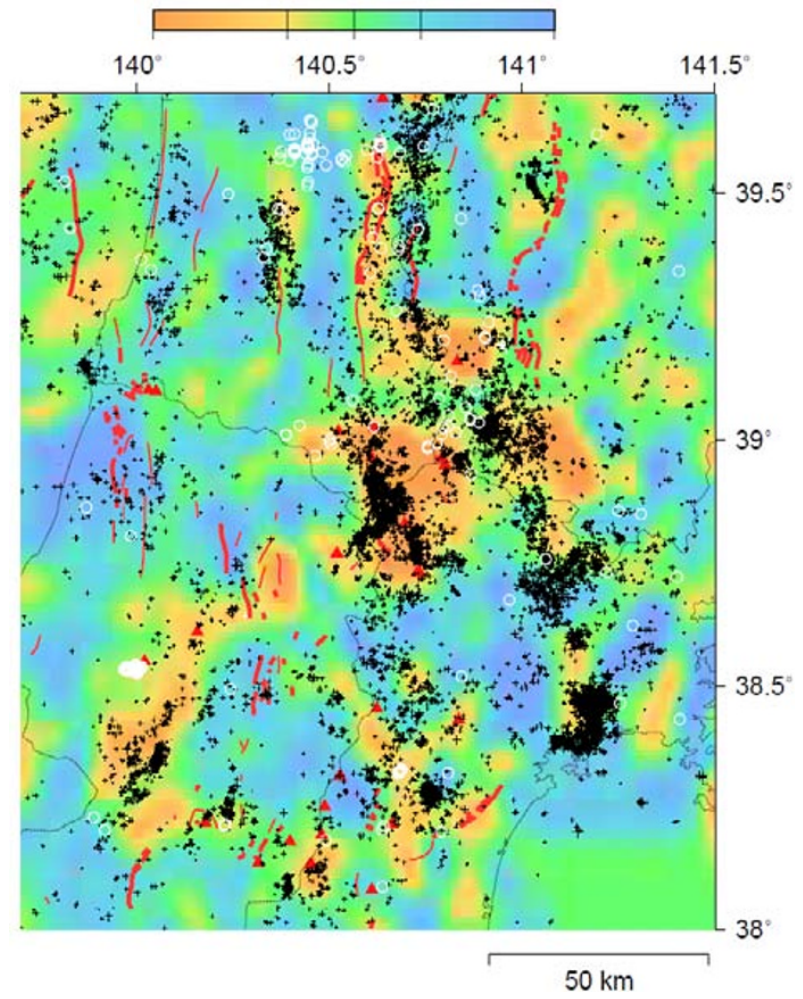

Fig. 4. $V_{s}$ perturbation at a depth of $18 \mathrm{~km}$ in a portion of northern Honshu (see Fig. 1) from Okada et al. (2010). Small crosses and white circles denote the epicenters of the earthquakes before, and after, the 2011 M9 earthquake, respectively. Triangles and red bold lines denote Quaternary volcanoes and active faults, respectively.

some areas (e.g. region 2.2). Hasegawa et al. (2011) have suggested that the change in the local stress regime is due to an almost complete stress drop in the $2011 M_{\mathrm{w}} 9.0$ Tohoku Earthquake. They also reported that near the focal areas of Kita-Ibaraki, and Iwaki, an earthquake of normal faulting occurred prior to the $2011 M_{\mathrm{w}} 9$ Tohoku earthquake from the NIED F-net catalog. In this study we have analyzed twelve earthquakes and it would be difficult to discuss the change in the stress regime in details. A detailed analysis of the focal mechanisms of the earthquakes following, and prior to, the $2011 M_{\mathrm{w}} 9$ Tohoku earthquake is necessary as a further study.

The seismically-active areas could be caused by the inelastic deformation of the crust brought about by a heterogeneous distribution of overpressured fluids (e.g. Hasegawa et al., 2009). Okada et al. (2010) have estimated a detailed seismic velocity structure in the central part of NE Japan using data obtained from a dense temporary seismic network. They found a distinct seismic low-velocity zone below the seismically-active areas (the seismic belt) along the volcanic front and fore-arc region. Figure 4 shows the distribution of post-megathrust events (white circles; Akita swarm, Yamagata-Gassan swarm and others), pre-megathrust events (black crosses) and the $V_{s}$ perturbation at a depth of $18 \mathrm{~km}$. The post-megathrust events were relocated by double-difference tomography (Zhang and Thurber, 2003) using the velocity structure of Okada et al. (2010). The post-megathrust events tend to be distributed above the edge of the seismic low-velocity zone in the lower crust. This suggests that an inhomogeneous structure of viscoelastic structure and overpressured fluid distribution in the lower crust (e.g. Miller et al., 2004) are spatially related to the distribution of the post-megathrust events. Not only is the elastic stress transfer/change, but also are the inelastic deformation and/or fluid redistribution, possibly important for understanding the interaction between the large subduction-thrust ruptures and the ensuring inland earthquake. This is a topic which is left for further studies.

\section{Conclusions}

We have estimated the fault planes of several remarkable inland earthquake sequences, that occurred actively after the $2011 M_{\mathrm{w}} 9.0$ Tohoku Earthquake, based on doubledifference location of earthquake hypocenters. We have also calculated the Coulomb stress change due to the 2011 $M_{\mathrm{w}} 9$ earthquake on these fault planes. The Coulomb stress change estimated for all the inferred fault planes are positive. This suggests that these inland earthquake sequences in the overriding plate of NE Japan just after the $2011 M_{\mathrm{w}} 9$ earthquake were triggered by a static stress transfer.

Acknowledgments. We have used data from JMA, Hi-net/NIED. This study is a part of a "Multidisciplinary research project for high strain rate zone" promoted by the Ministry of Education, Culture, Sports, Science and Technology (MEXT), Japan. Some of the temporary stations are operated cooperatively with the Japan $\mathrm{Nu}-$ clear Energy Safety Organization (JNES). We thank S. Miura, R. Hino, Y. Yabe, M. Ichiki, Y. Ito, Y. Ohta, T. Iinuma, M. Ohzono for valuable discussions. We acknowledge the seismic observations of T. Sato, S. Hori, K. Tachibana, T. Kono, T. Nakayama, S. Hirahara, S. Suzuki, T. Demachi and T. Kaida. We would like to thank the editor (Professor K. Yomogida), and the reviewers (Professor R. Sibson and an anonymous reviewer) for helpful comments. This work was conducted under the support of a Grant-in-Aid for Special Purposes, MEXT, Japan.

Group for the aftershock observations of the 2011 off the Pacific coast of Tohoku Earthquake consists of the members from Hokkaido University, Hirosaki University, Chiba University, University of Tokyo, Nagoya University, Kyoto University, Kochi University, Kyushu University, Kagoshima University, National Institute for Earth Sciences and Disaster Prevention, and Tohoku University.

\section{References}

Hardebeck, J. L. and P. M. Shearer, A New Method for Determining FirstMotion Focal Mechanisms, Bull. Seismol. Soc. Am., 92, 2264-2276, 2002.

Hasegawa, A., J. Nakajima, N. Umino, and S. Miura, Deep structure of the northeastern Japan arc and its implications for crustal deformation and shallow seismic activity, Tectonophysics, 403, 59-75, 2005.

Hasegawa, A., J. Nakajima, N. Uchida, T. Okada, D. Zhao, T. Matuzawa, and N. Umino, Plate subduction, and generation of earthquakes and magmas in Japan as inferred from seismic observations: An overview, Gondowana Res., 16, 370-400, 2009.

Hasegawa, A., K. Yoshida, and T. Okada, Nearly complete stress drop in the $2011 M_{\mathrm{w}} 9.0$ off the Pacific coast of Tohoku Earthquake, Earth Planets Space, 63, this issue, 703-707, 2011.

Hayes, G., Updated Result of the Mar 11, 2011 Mw 9.0 Earthquake Offshore Honshu, Japan, http://earthquake.usgs.gov/ earthquakes/eqinthenews/2011/usc0001xgp/finite_fault.php, 2011.

Iinuma, T., M. Ohzono, Y. Ohta, and S. Miura, Coseismic slip distribution of the 2011 off the Pacific coast of Tohoku Earthquake (M9.0) estimated based on GPS data-Was the asperity in Miyagi-oki ruptured?, Earth Planets Space, 63, this issue, 643-648, 2011. 
Kanamori, H., Mechanism of tsunami earthquakes, Phys. Earth Planet. Inter., 6, 346-359, 1972.

Lin, J. and R. S. Stein, Stress triggering in thrust and subduction earthquakes, and stress interaction between the southern San Andreas and nearby thrust and strike-slip faults, J Geophys Res, 109, 10.1029/2003JB002607, 2004.

Miller, S. A., C. Colletini, L. Chairaluce, M. Cocco, M. Marchi, and B. J. Kaus, Aftershocks driven by a high-pressure $\mathrm{CO} 2$ source at depth, Nature, 427, 724-727, 2004.

Nettles, M., G. Ekström, and H. C. Koss, Centroid-moment-tensor analysis of the 2011 off the Pacific coast of Tohoku Earthquake and its larger foreshocks and aftershocks, Earth Planets Space, 63, this issue, 519523, 2011.

Ohtake, M., A possibility that the 1896 Off Sanriku Great Earthquake Triggered the Riku U earthquake, Abstract for the 1997 JPGU Meeting, 1997.

Okada, T., N. Umino, and A. Hasegawa, Deep structure of the Ou mountain range strain concentration zone and the focal area of the 2008 IwateMiyagi Nairiku earthquake, NE Japan - Seismogenesis related with magma and crustal fluid, Earth Planets Space, 62, 347-352, 2010.

Okada, Y., Internal deformation due to shear and tensile faults in a half space, Bull. Seismol. Soc. Am., 82, 1018-1040, 1992.

Sato, H., N. Hirata, T. Iwasaki, M. Matsubara, and T. Ikawa, Deep seismic reflection profiling across the Ou Backbone range, northern Honshu Island, Japan, Tectonophysics, 355, 41-52, 2002.

Sibson, R. H., Rupture nucleation on unfavorably oriented faults, Bull.
Seismol. Soc. Am., 80, 1580-1604, 1990.

Sibson, R., Rupturing in overpressured crust during compressional inversion-the case from NE Japan, Tectonophysics, 473, 404-416, 2009.

Toda, S., http://www.rcep.dpri.kyotou.ac.jp/events/110311tohoku/toda/ index.html, 2011.

Toda, S., R. S. Stein, K. Richards-Dinger, and S. Bozkurt, Forecasting the evolution of seismicity in southern California: Animations built on earthquake stress transfer, J Geophys Res, B05S16, 10.1029/2004JB003415, 2005.

Waldhauser, F., HypoDD: A computer program to compute doubledifference hypocenter locations, US Geol. Surv. Open File Rep., 01-113, 25 pp. 2001.

Waldhauser, F. and W. L. Ellsworth, A double-difference earthquake location algorithm: method and application to the Northern Hayward fault, Bull. Seismol. Soc. Am., 90, 1353-1368, 2000.

Zhang, H. and C. Thurber, Double-Difference Tomography: the method and its application to the Hayward Fault, California, Bull. Seismol. Soc. Am., 93, 1875-1889, 2003.

T. Okada (e-mail: okada@aob.gp.tohoku.ac.jp), K. Yoshida, S. Ueki, J. Nakajima, N. Uchida, T. Matsuzawa, N. Umino, A. Hasegawa, and Group for the aftershock observations of the 2011 off the Pacific coast of Tohoku Earthquake 